\title{
Minimally Invasive Colorectal Surgery in the Morbidly Obese: Does High Body Mass Index Lead to Poorer Outcomes?
}

Eric M Haas ${ }^{1,2 *}$, Ali Aminian ${ }^{1,2}$, Javier Nieto ${ }^{1,2}$, Rodrigo Pedraza ${ }^{1,2}$, Carlos Martinez ${ }^{1,2}$, Chirag B Patel ${ }^{1,2}$ and Bartley Pickron T1,2

${ }^{1}$ Division of Minimally Invasive Colon and Rectal Surgery, Department of Surgery, The University of Texas Medical School at Houston, Houston, Texas, USA ${ }^{2}$ Colorectal Surgical Associates, Ltd, LLP, Houston, Texas, USA

\begin{abstract}
Background: Obesity is associated with increased surgical risk and major abdominal procedures performed in morbidly obese patients may prove challenging when compared with normal weight patients. There are limited data regarding outcomes after minimally invasive colorectal surgery in morbidly obese patients. The aim of this study was to compare the outcomes between morbidly obese and normal weight patients.

Materials and Methods: Forty morbidly obese were matched to three normal weight patients $(n=120)$, based on type of surgical approach and procedure. The patients underwent minimally invasive colorectal surgery by one of two colorectal surgeons. Patients were considered morbidly obese or normal-weight based on body mass index. Demographic data and operative outcomes were compared.

Results: Mean body mass index differed significantly between the morbidly obese (median $43.9 \mathrm{~kg} / \mathrm{m}^{2}$ ) and normal weight (median $22.7 \mathrm{~kg} / \mathrm{m}^{2}$ ) groups, $p<0.00001$. Both groups were comparable in regards to age, gender, history of prior abdominal operations, and clinical diagnosis. Surgical approaches included multiport laparoscopic colectomy (47.5\%), hand-assisted laparoscopic colectomy (35\%), robotic-assisted laparoscopic colectomy (12.5\%), and single-incision laparoscopic colectomy $(5 \%)$. The most common procedures were anterior resection $(42.5 \%)$ and right hemicolectomy (40\%). Morbidly obese patients required a significantly longer operative time (median $199 \mathrm{~min}$ vs. $139 \mathrm{~min}$, $p=0.0004$ ) and resulted in significantly greater blood loss (median $100 \mathrm{cc}$ vs. $75 \mathrm{cc}, \mathrm{p}=0.004$ ), with no higher conversion rate to open surgery $(7.5 \%$ vs. $2.5 \%, p=0.15)$ compared to normal weight patients. The mean length of hospital stay, 30 -day postoperative complication, readmission, and reoperation rates were comparable between groups.
\end{abstract}

Conclusions: Minimally invasive surgery for the treatment of colorectal disorders in morbidly obese patients results in short-term outcomes comparable to those observed in normal weight patients. Although technically challenging, morbidly obese population may benefit from minimally invasive surgery in regard to enhanced recovery.

Keywords: Minimally Invasive Surgery; Colorectal Surgery; Morbid Obesity; Colectomy

\section{Introduction}

Obesity has become an increasing health concern in the United States, affecting more than a third of the adult population [1], with almost 1 in 20 Americans being morbidly obese as defined with body mass index (BMI) of $40 \mathrm{~kg} / \mathrm{m}^{2}$ or greater [1,2]. The association between medical comorbidities (hypertension and diabetes mellitus) and obesity has been well established. Although obesity can lead to cardiovascular, metabolic, and pulmonary disease, it is additionally associated with an increased surgical risk and postoperative complication rate [3-6].

Minimally Invasive Surgery (MIS) for the treatment of colorectal diseases has been shown to provide several advantages over an open approach including decreased postoperative pain, improved pulmonary function, lower wound complication rate, and faster postoperative recovery resulting in shorter hospital stay $[7,8]$. Nevertheless, the impact of these advantages in the obese population has yet to be fully evaluated [9-11]. The available studies to date have compared outcomes of laparoscopic colectomy in obese patients (BMI $\left.>30 \mathrm{~kg} / \mathrm{m}^{2}\right)$ versus non-obese patients $\left(\mathrm{BMI}<30 \mathrm{~kg} / \mathrm{m}^{2}\right)$ including normal- and overweight patients, and have revealed higher conversion rate and worse postoperative outcomes in the obese patients $[4,12,13]$. However, the effect of MIS on the subset of patients who are morbidly obese $(\geq 40 \mathrm{~kg} /$ $\mathrm{m}^{2}$ ) has not been specifically addressed in the surgical literature [9]. The aim of this study was to compare short-term outcomes of minimally invasive colorectal surgery between Morbidly Obese (MO) and Normal Weight (NW) patients.

\section{Materials and Methods}

One thousand and eight consecutive patients underwent MIS for benign or malignant colorectal diseases between January 2006 and December 2011 in our practice. The surgical approach included Conventional Laparoscopic Colectomy (CLC), Hand-assisted Laparoscopic Colectomy (HALC), Robotic-assisted Laparoscopic Colectomy (RALC), and Single Incision Laparoscopic Colectomy (SILC). Of these cases, 40 patients were MO using BMI as an objective parameter to categorize body weight in accordance with the WHO classification, BMI $\geq 40 \mathrm{~kg} / \mathrm{m}^{2}$. These cases were each randomly matched with three cases involving NW patients $\left(18.5 \mathrm{~kg} / \mathrm{m}^{2} \leq \mathrm{BMI}\right.$ $<25 \mathrm{~kg} / \mathrm{m}^{2}, \mathrm{n}=120 \mathrm{NW}$ cases) based on two matching criteria: type of MIS approach and type of colorectal procedure.

Demographic data, intraoperative parameters, and postoperative outcomes were collected and entered prospectively into an Institutional Review Board-approved database for retrospective analysis. Demographic data including age, gender, BMI, American Society of Anesthesiologist (ASA) score and history of prior abdominal surgery were tabulated. Intraoperative parameters including Estimated Blood

*Corresponding author: Eric M Haas, Colorectal Surgical Associates, Ltd, LLP, 7900 Fannin Street, Suite 2700, Houston, TX 77054, USA, Tel: 713-790-0600; Fax 713-790-0616; E-mail: ehaasmd@houstoncolon.com

Received August 08, 2013; Accepted October 15, 2013; Published October 27 2013

Citation: Haas EM, Aminian A, Nieto J, Pedraza R, Martinez C, et al. (2013) Minimally Invasive Colorectal Surgery in the Morbidly Obese: Does High Body Mass Index Lead to Poorer Outcomes? Surgery Curr Res 3: 149. doi:10.4172/21611076.1000149

Copyright: ( 2013 Haas EM, et al. This is an open-access article distributed under the terms of the Creative Commons Attribution License, which permits unrestricted use, distribution, and reproduction in any medium, provided the original author and source are credited. 
Loss (EBL), Total Operative Time (OT), and conversion rate were analyzed. Postoperative outcomes including length of hospital stay (LOS), complication rate, readmission rate, and reoperation rate were assessed. Each procedure was performed by one of two board-certified colorectal surgeons (E. M. H. and T. B. P.) and the operative technique for the different minimally invasive procedures has been previously described [14-21].

Data were analyzed using Stata (StataCorp LP, College Station, TX). Continuous parameters are presented as mean \pm standard deviation, or median and range. Categorical data are expressed as frequency (\%). Comparative analysis was performed with Student's t-test for normally-distributed continues variables, Wilcoxon rank-sum test for non-normally distributed continuous variables, and chi-square or Fisher's exact tests for categorical variables. Logistic regression analysis was performed to determine odds ratios. $\mathrm{P}<0.05$ was considered to be statistically significant.

\section{Results}

The median BMI for the $\mathrm{MO}$ and NW groups was $43.9 \mathrm{~kg} / \mathrm{m}^{2}$ (range $40-61.8 \mathrm{~kg} / \mathrm{m}^{2}$ ) and $22.7 \mathrm{~kg} / \mathrm{m}^{2}$ (range $18.5-24.9 \mathrm{~kg} / \mathrm{m}^{2}$ ), respectively $(\mathrm{p}<0.00001)$. There was no significant difference between the groups in regards to age $(p=0.15)$, gender $(p=1)$, history of prior abdominal operations $(\mathrm{p}=0.12)$, and surgeon distribution $(\mathrm{p}=0.08)$. The ASA score was significantly greater in the MO group $(2.8 \pm 0.5)$ compared to the NW group $(2.3 \pm 0.6), \mathrm{p}=0.0001$ (Table 1 ). The colorectal MIS approaches included multiport CLC (47.5\%), HALC (35\%), RALC (12.5\%), and SILC (5\%). The groups did not differ in terms of clinical diagnosis $(\mathrm{p}=0.47)$ or presence of malignancy on histopathologic examination $(\mathrm{p}=0.93)$. The most common procedure was anterior resection $(42.5 \%)$, followed by right hemicolectomy (40\%), left colectomy (5\%), low anterior resection (5\%), abdominoperineal resection (5\%), and subtotal colectomy (2.5\%) (Table 2).

In regard to the intraoperative parameters, the MO group had a significantly longer OT (median $199 \mathrm{~min}$ ) compared to the NW group (median $139 \mathrm{~min}$ ), $\mathrm{p}=0.0004$. There was significantly greater blood loss in the MO group (median $100 \mathrm{ml}$ ) compared to the NW group (median $75 \mathrm{ml}$ ), $\mathrm{p}=0.004$ (Table 3). There was no significant difference in intraoperative complication rate $(7.5 \%$ in the $\mathrm{MO}$ group and $4.2 \%$ in the NW group, $\mathrm{p}=0.40)$. There was no significant difference in the rate of conversion to open surgery between the $\mathrm{MO}$ and $\mathrm{NW}$ groups $(7.5 \%$ vs. $2.5 \%$ respectively, $\mathrm{p}=0.15$ ). However, the odds ratio of conversion from any non-HALC approach to HALC was 14 for MO compared to NW patients, $p=0.02$. In the subset of converted patients to HALC, no significant difference was observed in the LOS $(4.8 \pm 1.9$ vs. $4.6 \pm 4.6$, $\mathrm{p}=0.94)$ or complication rate $(20 \%$ vs. $22.2 \%, \mathrm{p}=1)$.

\begin{tabular}{|l|c|c|c|}
\hline Parameters & $\begin{array}{c}\text { Morbid obesity } \\
(\mathbf{n = 4 0 )}\end{array}$ & $\begin{array}{c}\text { Normal weight } \\
(\mathbf{n = 1 2 0 )}\end{array}$ & p-value \\
\hline Gender (F, \%) & $23(57.5 \%)$ & $69(57.5 \%)$ & 1 \\
\hline Age (years) & $56.3 \pm 11.0$ & $60.0 \pm 15.1$ & 0.15 \\
\hline BMI $\left(\mathrm{kg} / \mathrm{m}^{2}\right)$ & $44.6 \pm 4.6$ & $22.5 \pm 1.9$ & $\mathrm{~N} / \mathrm{A}$ \\
\hline \multicolumn{1}{|c|}{ median, range } & $43.9,40-61.8$ & $22.7,18.5-24.9$ & $<0.00001^{*}$ \\
\hline ASA score & $2.8 \pm 0.5$ & $2.3 \pm 0.6$ & $0.0001^{*}$ \\
\hline $\begin{array}{l}\text { Prior abdominal } \\
\text { surgeries (\%) }\end{array}$ & $23(57.5 \%)$ & $52(43.3 \%)$ & 0.12 \\
\hline Surgeon distribution & & & 0.08 \\
\hline \multicolumn{1}{|c|}{ E.M.H. (\%) } & $25(62.5 \%)$ & $92(76.7 \%)$ & \\
\hline T.B.P. (\%) & $15(37.5 \%)$ & $28(23.3 \%)$ & \\
\hline
\end{tabular}

*Statistically significant, ASA: American Society of Anesthesiologists, BMI: Body Mass Index, N/A: Not Applicable

Table 1: Preoperative characteristics.
The hospital LOS was comparable between the two groups (median 4 days in the $\mathrm{MO}$ group and 3 days in the NW group), $\mathrm{p}=0.08$. The overall postoperative complication rate was greater in the MO group (30\%) compared to the NW group (17.5\%), but did not reach statistical significance $(\mathrm{p}=0.09)$. The most frequent complications encountered in the $\mathrm{MO}$ and NW groups were prolonged ileus ( $7.5 \%$ vs. $4.2 \%$, respectively, $\mathrm{p}=0.41)$, wound infection ( $5 \%$ vs. $0.8 \%$, respectively, $\mathrm{p}=0.15$ ), and anastomotic leak ( $2.5 \%$ vs. $1.7 \%$, respectively, $\mathrm{p}=1$ ) (Table 4$)$. Reoperation within 30 days was necessary in $1 \mathrm{MO}$ patient $(2.5 \%)$ and $6 \mathrm{NW}$ patients $(5 \%), \mathrm{p}=0.50$. The most frequent indication for reoperation was anastomotic leak ( $\mathrm{n}=3$ cases). Overall two of the abdominal reoperations (33.3\%) were performed with MIS approach. The 30-day readmission rate was comparable between the MO group (12.5\%) and NW group (8.3\%), $\mathrm{p}=0.43$. There was one 30 -day postoperative mortality in the NW group $(0.8 \%)$ and none in the MO group $(\mathrm{p}=1)$.

\section{Discussion}

With $35.7 \%$ of the American population categorized as such, obesity is now considered an epidemic [1,2,22]. Even more alarming is the prevalence of morbid obesity which is increasing at a rate twice as fast as obesity [2]. The medical conditions associated with obesity (e.g., hyperlipidemia, diabetes mellitus, and cardiovascular disease) are well-recognized co morbid factors that can negatively impact operative outcomes [5,6]. In those who are morbidly obese, these co morbid conditions may be even more profound. In a recent study involving the American College of Surgeons National Surgical Quality Improvement Program (ACS-NSQIP) dataset, MO patients who underwent open colon resection for malignant disease had a significantly higher risk of surgical site infection ( $20.7 \%$ vs. $9.0 \%)$, dehiscence (3.3\% vs. $1.1 \%)$, pulmonary embolism ( $1.3 \%$ vs. $0.3 \%)$, and renal failure (3.0\% vs. $1.5 \%)$ when compared with NW patients, respectively [23].

Minimally invasive colorectal surgery is now widely accepted as a

\begin{tabular}{|c|c|c|c|}
\hline Parameters & $\begin{array}{l}\text { Morbid obesity } \\
\quad(n=40)\end{array}$ & $\begin{array}{l}\text { Normal weight } \\
\quad(n=120)\end{array}$ & p-value \\
\hline Clinical diagnosis (\%) & & & 0.47 \\
\hline Cancer & $14(35 \%)$ & $47(39 \%)$ & \\
\hline Polyp & $14(35 \%)$ & $24(20 \%)$ & \\
\hline Diverticulitis & $10(25 \%)$ & $37(31 \%)$ & \\
\hline Crohn's disease & $1(2.5 \%)$ & $4(3 \%)$ & \\
\hline Ulcerative colitis & $1(2.5 \%)$ & $5(4 \%)$ & \\
\hline Rectal prolapse & 0 & $3(3 \%)$ & \\
\hline Surgical approach (\%) & & & 1 \\
\hline Conventional LC & $19(47.5 \%)$ & $57(47.5 \%)$ & \\
\hline Hand-assisted LC & $14(35 \%)$ & $42(35 \%)$ & \\
\hline Robotic-assisted LC & $5(12.5 \%)$ & $15(12.5 \%)$ & \\
\hline Single-incision LC & $2(5 \%)$ & $6(5 \%)$ & \\
\hline Operative procedure (\%) & & & 1 \\
\hline Right colectomy & $16(40 \%)$ & $48(40 \%)$ & \\
\hline Left colectomy & $2(5 \%)$ & $6(5 \%)$ & \\
\hline Anterior resection & $17(42.5 \%)$ & $51(42.5 \%)$ & \\
\hline Low anterior resection & $2(5 \%)$ & $6(5 \%)$ & \\
\hline $\begin{array}{l}\text { Abdomino-perineal } \\
\text { resection }\end{array}$ & $2(5 \%)$ & $6(5 \%)$ & \\
\hline Subtotal colectomy & $1(2.5 \%)$ & $3(2.5 \%)$ & \\
\hline Pathology (\%) & & & 0.93 \\
\hline Malignant & $23(57.5 \%)$ & $70(58 \%)$ & \\
\hline Benign & $17(42.5 \%)$ & $50(42 \%)$ & \\
\hline
\end{tabular}

LC: Laparoscopic Colectomy

Table 2: Diagnosis and operations 


\begin{tabular}{|l|c|c|c|}
\hline Parameters & $\begin{array}{c}\text { Morbid obesity } \\
(\mathbf{n = 4 0 )}\end{array}$ & $\begin{array}{c}\text { Normal weight } \\
(\mathbf{n = 1 2 0})\end{array}$ & $\mathbf{p}$-value \\
\hline Operative time (min) & $203.8 \pm 88.8$ & $149.2 \pm 63.2$ & $\mathrm{~N} / \mathrm{A}$ \\
\hline median, range & $199,70-420$ & $139,70-420$ & $0.0004^{*}$ \\
\hline Estimated blood loss (ml) & $223.75 \pm 467.3$ & $115.5 \pm 164.2$ & $\mathrm{~N} / \mathrm{A}$ \\
\hline median, range & $100,25-3000$ & $75,25-1200$ & $0.004^{*}$ \\
\hline Complications (\%) & $3(7.5 \%)$ & $5(4.2 \%)$ & 0.40 \\
\hline Bleeding (\%) & $2(5 \%)$ & $3(2.5 \%)$ & 0.60 \\
\hline Bladder injury (\%) & $1(2.5 \%)$ & 0 & 0.25 \\
\hline Ureteral injury (\%) & 0 & $1(0.8 \%)$ & 1 \\
\hline Bowel thermal injury (\%) & 0 & $1(0.8 \%)$ & 1 \\
\hline Conversion to open (\%) & $3(7.5 \%)$ & $3(2.5 \%)$ & 0.15 \\
\hline Failure to progress (\%) & $1(2.5 \%)$ & $2(1.7 \%)$ & \\
\hline Bleeding (\%) & $1(2.5 \%)$ & 0 & \\
\hline Presence of large colonic mass (\%) & $1(2.5 \%)$ & 0 & \\
\hline Presence of large ovarian mass (\%) & 0 & $1(0.8 \%)$ & \\
\hline Conversion to Hand-assisted LC (\%) & $4 / 26(15.4 \%)$ & $1 / 78(1.3 \%)$ & $0.004^{*}$ \\
\hline Failure to progress (\%) & $3(11.5 \%)$ & $1(1.3 \%)$ & \\
\hline Inability to maintain & $1(3.8 \%)$ & 0 & \\
\hline pneumoperitoneum (\%) & & & \\
\hline
\end{tabular}

*Statistically significant, LC: Laparoscopic Colectomy, N/A=Not Applicable

Table 3: Intraoperative data.

\begin{tabular}{|l|c|c|c|}
\hline Parameters & $\begin{array}{c}\text { Morbid obesity } \\
(\mathbf{n = 4 0 )}\end{array}$ & $\begin{array}{c}\text { Normal weight } \\
(\mathbf{n = 1 2 0})\end{array}$ & p-value \\
\hline Complications (\%) & $12(30 \%)$ & $21(17.5 \%)$ & 0.09 \\
\hline Prolonged ileus (\%) & $3(7.5 \%)$ & $5(4.2 \%)$ & 0.41 \\
\hline Wound infection (\%) & $2(5 \%)$ & $1(0.8 \%)$ & 0.15 \\
\hline Anastomotic leak (\%) & $1(2.5 \%)$ & $2(1.7 \%)$ & 1 \\
\hline Abdominal/pelvic abscess (\%) & $1(2.5 \%)$ & $2(1.7 \%)$ & 1 \\
\hline Deep vein thrombosis (\%) & $1(2.5 \%)$ & 0 & 0.25 \\
\hline Length of stay (days) & $4.9 \pm 3.4$ & $5.1 \pm 5.6$ & $\mathrm{~N} / \mathrm{A}$ \\
\hline median, range & $4,2-20$ & $3,2-40$ & 0.08 \\
\hline 30-day Readmission Rate (\%) & $5(12.5 \%)$ & $10(8.3 \%)$ & 0.43 \\
\hline 30-day Reoperation Rate (\%) & $1(2.5 \%)$ & $6(5 \%)$ & 0.50 \\
\hline Mortality (\%) & 0 & $1(0.8 \%)$ & 1 \\
\hline
\end{tabular}

$\mathrm{N} / \mathrm{A}=$ Not Applicable

\section{Table 4: Postoperative data.}

surgical approach for both malignant and benign colorectal diseases with advantages that may be more pronounced in high-risk patients $[7,8]$. Although studies regarding the role of the MIS approach in the treatment of colorectal diseases in obese patients have been published [4,6,10-12,24-27], feasibility and safety of MIS in the subset of patients with $\mathrm{MO}$ is not widely reported [9]. Mustain et al. [27] reviewed a multi-institutional NSQIP dataset to determine the effect of BMI on outcomes following minimally invasive colorectal surgery and noted a positive correlation between OT and BMI class, independent of other variables. Obesity was also an independent risk factor for superficial wound infection; however, major morbidity and mortality rates were similar among the groups [27]. In a recent comprehensive metaanalysis evaluating the impact of obesity on Perioperative outcomes after minimally invasive colorectal surgery (the analysis included one study involving MO patients), obesity was associated with longer OT and higher rates of conversion to open surgery secondary to limited exposure of the operative field and difficult dissection. However, a negative impact of obesity on intraoperative blood loss, perioperative mortality and reoperation rate was not observed [6].

Khoury et al. [9] compared the short-term outcomes following LC between $36 \mathrm{MO}$ patients and 36 control patients with $\mathrm{BMI}<30 \mathrm{~kg} / \mathrm{m}^{2}$ and found comparable results in regards to OT(177.9 $\pm 89.1 \mathrm{~min}$ vs. $136.4 \pm 71.3 \mathrm{~min}, \mathrm{p}=0.12)$, EBL $(222.3 \pm 196.4 \mathrm{ml}$ vs. $157.1 \pm 140.7$ $\mathrm{ml}, \mathrm{p}=0.1)$, conversion rate $(13.9 \%$ vs. $8.3 \%, \mathrm{p}=0.7)$, median LOS $(4.5$ days vs. 4 days, $\mathrm{p}=0.2)$, and postoperative complication rate $(27.8 \%$ vs. $47.2 \%, p=0.14$ ), respectively [9]. In the current study, we aimed to explore the benefits and limitations of the minimally invasive platform in the MO subset of high-risk patients to determine the feasibility and utility of this approach. On average the operative time was $54.6 \mathrm{~min}$ longer in the MO patients compared to the NW patients. This result is consistent with the abovementioned studies and was largely due to loss of abdominal domain, poor exposure and a relatively confined operative field of view. We encountered technical challenges with retraction of the characteristic shortened and thickened small bowel and colonic mesentery and considerable limitations in the ability to tilt the table to extreme angles for optimal utilization of gravitational forces. Furthermore, the MO patients tended to be sensitive to elevated peak airway pressures with even moderate Trendelenburg, necessitating frequent interruption of the procedures to provide normalization of pressures.

Despite the greater intraoperative blood loss, prolonged operative times and anatomical challenges, there was no overall significant difference between the groups in regards to conversion to open procedures. During the course of the study, HALC was noted to be an excellent platform to overcome many of the limitations in exposure and positioning by using the surgeon's hand as a large retractor. The odds ratio of conversion to HALC was 14 for MO compared to NW patients. The main reason for conversion was failure to progress secondary to restricted and inadequate exposure. In the subset of converted patients to HALC, no significant difference was observed in the LOS or complication rate. Similar results have been observed in other studies involving a mixed population in which those converted to HALC recovered in a similar fashion to those who did not; whereas those converted to open fared poorly $[19,28]$.

Considering that the MO patients are classified as high-risk when compared to NW patients, one would expect a higher rate of complications, prolonged LOS, and a greater incidence of reoperation and readmissions $[4,12,13]$ in the MO group. In this study however, the incidence of postoperative complication rate, including wound infection as well as the reoperation rate, was not found to be significantly higher in the MO patients. Furthermore, LOS, readmission rate, and mortality rate were comparable between the $\mathrm{MO}$ and $\mathrm{NW}$ groups. Thus, performing minimally invasive colon resection surgery in the MO may serve as an equalizer in regards to postoperative outcomes since the outcomes approach those in the NW group.

To our knowledge this is the largest matched case-control study to address the effects of morbid obesity on the surgical outcomes of MIS for colorectal diseases. To minimize the effect of confounding factors, each MO patient was matched with three NW patients based on two matching criteria: type of MIS approach and type of colorectal procedure. However, this study is limited by the retrospective design and the relatively small number of patients of a single surgical service, which may account for differences in complication rates not reaching statistical significance. Furthermore, selection bias could have had an effect because BMI $>40 \mathrm{~kg} / \mathrm{m}^{2}$ corresponded with greater ASA score, which could account for an expectation of higher complication rates in the MO cohort. However, the observed complication rates results in this study may reflect the positive impact of advantages of MIS when utilized in the population of $\mathrm{MO}$ patients.

In conclusion, minimally invasive surgery for the treatment of colorectal disorders in MO patients results in short-term outcomes 
Citation: Haas EM, Aminian A, Nieto J, Pedraza R, Martinez C, et al. (2013) Minimally Invasive Colorectal Surgery in the Morbidly Obese: Does High Body Mass Index Lead to Poorer Outcomes? Surgery Curr Res 3: 149. doi:10.4172/2161-1076.1000149

Page 4 of 4

comparable to those observed in NW patients. Although MIS is a technically challenging procedure in the MO population, it may benefit this high-risk population in regard to enhanced recovery. Comparative analysis and larger cohorts of patients will be necessary to enumerate the extent of the benefits and limitations in MO patients.

\section{Acknowledgement}

EMH was responsible for the conception and design of this manuscript. EMH $\mathrm{AM}, \mathrm{JN}, \mathrm{RP}, \mathrm{CM}, \mathrm{CBP}$ and TBP were responsible for drafting the manuscript, revising it critically for important intellectual content, and providing final approval.

\section{Funding Support}

There are no funding sources or financial relationships to disclose.

\section{Presentation}

Poster presentation at the meeting of The American Society of Colon and Rectal Surgeons, San Antonio, TX, June 2-6, 2012.

\section{References}

1. Ogden CL, Carroll MD, Kit BK, Flegal KM (2012) Prevalence of obesity in the United States, 2009-2010. NCHS Data Brief: 1-8.

2. Hensrud DD, Klein S (2006) Extreme obesity: a new medical crisis in the United States. Mayo Clin Proc 81: S5-10.

3. Choban PS, Flancbaum L (1997) The impact of obesity on surgical outcomes: a review. J Am Coll Surg 185: 593-603.

4. Benoist S, Panis $Y$, Alves A, Valleur $P$ (2000) Impact of obesity on surgical outcomes after colorectal resection. Am J Surg 179: 275-281.

5. Bellanger TM, Bray GA (2005) Obesity related morbidity and mortality. J La State Med Soc 157 Spec No 1: S42-49.

6. Makino T, Shukla PJ, Rubino F, Milsom JW (2012) The impact of obesity on perioperative outcomes after laparoscopic colorectal resection. Ann Surg 255: 228-236.

7. Bilimoria KY, Bentrem DJ, Merkow RP, Nelson H, Wang E, et al. (2008) Laparoscopic-assisted vs. open colectomy for cancer: comparison of shortterm outcomes from 121 hospitals. J Gastrointest Surg 12: 2001-2009.

8. Bonjer HJ, Hop WC, Nelson H, Sargent DJ, Lacy AM, et al. (2007) Laparoscopically assisted vs open colectomy for colon cancer: a meta-analysis. Arch Surg 142: 298-303.

9. Khoury W, Kiran RP, Jessie T, Geisler D, Remzi FH (2010) Is the laparoscopic approach to colectomy safe for the morbidly obese? Surg Endosc 24: 13361340.

10. Dostalík J, Martínek L, Vávra P, Andel P, Gunka I, et al. (2005) Laparoscopic colorectal surgery in obese patients. Obes Surg 15: 1328-1331.

11. Tuech JJ, Regenet N, Hennekinne S, Pessaux P, Bergamaschi R, et al. (2001) Laparoscopic colectomy for sigmoid diverticulitis in obese and nonobese patients: a prospective comparative study. Surg Endosc 15: 1427-1430.

12. Pikarsky AJ, Saida Y, Yamaguchi T, Martinez S, Chen W, et al. (2002) Is obesity a high-risk factor for laparoscopic colorectal surgery? Surg Endosc 16: 855858.
13. Tekkis PP, Senagore AJ, Delaney CP (2005) Conversion rates in laparoscopic colorectal surgery: a predictive model with, 1253 patients. Surg Endosc 19 : 47-54

14. Patel CB, Ragupathi M, Ramos-Valadez DI, Haas EM (2011) A threearm (laparoscopic, hand-assisted, and robotic) matched-case analysis of intraoperative and postoperative outcomes in minimally invasive colorectal surgery. Dis Colon Rectum 54: 144-150.

15. Pedraza R, Ramos-Valadez DI, Haas EM (2011) Robotic-assisted laparoscopic surgery of the colon and rectum: a literature review. Cir Cir 79: 384-391.

16. Patel CB, Ramos-Valadez DI, Haas EM (2010) Robotic-assisted laparoscopic abdominoperineal resection for anal cancer: feasibility and technical considerations. Int J Med Robot 6: 399-404.

17. Ramos-Valadez DI, Ragupathi M, Nieto J, Patel CB, Miller S, et al. (2012) Single-incision versus conventional laparoscopic sigmoid colectomy: a casematched series. Surg Endosc 26: 96-102.

18. Ramos-Valadez DI, Patel CB, Ragupathi M, Bokhari MB, Pickron TB, et al. (2011) Single-incision laparoscopic colectomy: outcomes of an emerging minimally invasive technique. Int J Colorectal Dis 26:761-767.

19. Gandhi DP, Ragupathi M, Patel CB, Ramos-Valadez DI, Pickron TB, et al. (2010) Single-incision versus hand-assisted laparoscopic colectomy: a casematched series. J Gastrointest Surg 14: 1875-1880.

20. Ramos-Valadez DI, Patel CB, Ragupathi M, Bartley Pickron T, Haas EM (2010) Single-incision laparoscopic right hemicolectomy: safety and feasibility in a series of consecutive cases. Surg Endosc 24: 2613-2616.

21. World Health Organization, media centre. BMI classification.

22. Flegal KM, Carroll MD, Ogden CL, Curtin LR (2010) Prevalence and trends in obesity among US adults, 1999-2008. JAMA 303: 235-241.

23. Merkow RP, Bilimoria KY, McCarter MD, Bentrem DJ (2009) Effect of body mass index on short-term outcomes after colectomy for cancer. J Am Coll Surg 208: 53-61.

24. Delaney CP, Pokala N, Senagore AJ, Casillas S, Kiran RP, et al. (2005) Is laparoscopic colectomy applicable to patients with body mass index $>30$ ? A case-matched comparative study with open colectomy. Dis Colon Rectum 48: 975-981.

25. Zhou Y, Wu L, Li X, Wu X, Li B (2012) Outcome of laparoscopic colorecta surgery in obese and nonobese patients: a meta-analysis. Surg Endosc 26: 783-789.

26. Leroy J, Ananian P, Rubino F, Claudon B, Mutter D, et al. (2005) The impact of obesity on technical feasibility and postoperative outcomes of laparoscopic left colectomy. Ann Surg 241: 69-76.

27. Mustain WC, Davenport DL, Hourigan JS, Vargas HD (2012) Obesity and laparoscopic colectomy: outcomes from the ACS-NSQIP database. Dis Colon Rectum 55: 429-435.

28. Gonzalez R, Smith CD, Mason E, Duncan T, Wilson R, et al. (2006) Consequences of conversion in laparoscopic colorectal surgery. Dis Colon Rectum 49: 197-204. 